\title{
El arte médico y el papel de la clínica hoy
}

\author{
Douglas Maza-González 凶
}

Médico pediatra y neumopediatra. Ex adscrito al Servicio de Neumopediatría del INER, Cancún, Quintana Roo, México. Trabajo recibido: 06-X-2014; aceptado: 08-X-2014

\begin{abstract}
Al Dr. Fernando Rébora Gutiérrez. In memóriam A la Dra. Genny Santamaría, Dr. Francisco Colon

La medicina es la más humana de las ciencias y la más científica de las artes.

Dr. Ignacio Chávez
\end{abstract}

En todos los siglos precedentes de nuestra civilización occidental, el médico asumía con sensibilidad el sufrimiento de sus semejantes, era una figura apreciada primero como aprendiz de brujo, luego chamán. A inicios de nuestra modernidad, el médico asumió su profesión como arte y no como ciencia.

Para ser explicito en esto, el arte médico es un arte muy peculiar que se origina en occidente con los sofistas griegos, quedando atrás la figura de curandero rodeado de un halo de poder mágico, para pasar a hombre de ciencia. Bajo los conceptos griegos de logos es decir, el libre reconocimiento pensante de las cosas y de techné, que es el saber que representa una habilidad, un conocimiento técnico, Aristóteles es el primero en emplear la medicina como un ejemplo típico de ciencia, poniendo al médico en ventaja frente al curandero, por su comprensión del fenómeno estudiado.

La esencia peculiar del arte médico de curar consiste, más bien, en poder producir lo ya producido por la naturaleza; es decir, lo que el médico reproduce es el restablecimiento de la salud en el enfermo. Aquí se aplica la vieja expresión de que estar sano no es estar curado y con base en interrogante que esto genera, ¿hasta qué medida el médico influyó con su diagnóstico y tratamiento acertado sobre el enfermo, y en qué medida fue la propia naturaleza del paciente la que se autorreguló? Lo que el arte de curar debe producir es la salud, en tanto que restablece lo que estaba perturbado. ${ }^{1}$

El aprendiz de médico vive un período de enamoramiento cuando se adentra primerizo en las ciencias de lo humano, para luego pasar a un período de perplejidad, porque dos más dos no es igualmente reproducible en biología que en otras ciencias como las matemáticas, la química o la física. Lo biológico se organiza en leyes aleatorias aun totalmente incomprendidas, grados de entropía que nos dejan perplejos y hace que predomine siempre un ambiente de incertidumbre en la ciencia médica.

El azar, que juega un papel principal en la vida, hace al conocimiento médico más inasible y el pronóstico siempre es aleatorio. El médico debe estar siempre preparado para hacer lo que mejor sabe, lo que mejor puede y lo que mejor debe, ante la incertidumbre que genera la influencia de lo nuevo, que como moda es factible de constantes cambios. Lo nuevo se ha demostrado que no garantiza el progreso absoluto.

El médico de nuestro tiempo tiene en contra el tiempo acelerado de los descubrimientos científicos, y está cada vez menos educado para pensar según las diferentes formas de la lógica (formal, científica, matemática...) y su capacidad de reflexión inmediata es limitada. Se remite a una suerte de «clinimetría» donde es más fácil ponerle número y score a los síntomas/ signos que cualidades, como si con ello pudiera definir una constante absoluta sobre tal o cual padecimiento. La experiencia y la capacidad de reflexión en el clínico juegan un papel determinante para tender un puente entre la enfermedad y la curación, esto requiere a la final mucha medicina basada en la experiencia observacional, legado ya por la clínica tradicional a través de la historia, ${ }^{2} \sin$ soslayar claro está las constantes tecnológicas de cada presente, al alcance en su entorno de trabajo bajo los recursos y circunstancias económicas específicas.

Para ejemplificar y retomar la cosmología clínica, tomemos el caso de la semiología del dolor como constante cardinal de la humanidad, sea este definido como síntoma o como enfermedad. En los albores de la vida o de la aparición del hombre sobre la tierra, el dolor ha pervivido como un mecanismo de defensa ante los 
peligros del entorno vivo. Hoy sabemos por los avances en anestesiología, por hallazgos anatómicos y neurofisiológicos de Bell, Magendie, Shiff a la actualidad, que éste obedece a estímulos específicos dependientes de receptores estereoespecíficos que son saturables por opiáceos en el sistema nervioso.

Lo concreto es que la experiencia del dolor puede ser transferencial del enfermo al médico, pero es sabido que el dolor del otro es mejor tolerado que el propio. No será posible definir conceptualmente el dolor como una sensación puramente somática cuantificable y, seguramente, no podrá serlo, al igual como ocurre con las otras sensaciones de daño síquico que son definidas como sufrimiento, conceptualizados por Sigmund Freud de traumatismos síquicos transferibles a síntomas somáticos.

La actitud del médico ante el dolor causado por una enfermedad aguda o crónica pone en juego su experiencia clínica. El dolor agudo es una contingencia que puso en juego desde el hombre primitivo la habilidad de aplicar métodos físicos, hierbas o drogas analgésicas o intoxicantes para bloquearlo, posteriormente la cirugía tomó un papel más preponderante con el avance de los medios de esterilización y antisepsia.

En el dolor agudo entran en juego más las habilidades y la tecnología, es por tanto, un accionar del cerebelo en el hombre ante el peligro inmediato. Pero el verdadero reto del humano es el dolor crónico o intercurrente, para esto el hombre debe echar a andar su corteza pensante y reflexiva utilizando los recursos del legado clínico. Por lo tanto, el dolor crónico es trascendente en comparación con lo contingente del dolor agudo. La recurrencia transciende lo inmediato e impone a largo plazo la cronicidad, porque implica diversos conflictos en las defensas del organismo hasta llevarlo a alteraciones psíquicas; los pacientes manifiestan depresión, angustia, insomnio, mal estado general. Así, en palabras del Dr. Gerardo Romero, «... el dolor no debe entenderse únicamente como un problema que implica la transmisión de impulsos nerviosos, sino como una experiencia que afecta la personalidad del individuo y da lugar a cambios profundos en el proceso cultural y biológico que constituyen la vida».3. Concretando, entonces, el hombre es una unidad biológica, sicológica y social. Esta tríada fue ya consensuada por la OMS como definitoria del bienestar humano.

La clínica clásica cada día se ve confrontada por el complejo farmacoindustrial. Los médicos se ven obligados a usar la tecnología cada vez más, se estimula la demanda y el médico siente amenazada su sobrevivencia si no va a la par de ella. Esto complica mucho el panorama en una sociedad en desarrollo, que carece aún de recursos económicos aplicables a todos los niveles de atención.

Cada día los médicos de experiencia coinciden en que la medicina debe regresar a los nosocomios, salirse de los salones de clase porque el enfermo es un ente irremplazable para nutrir la ars medica. Los antiguos rituales a la cabecera del paciente, bajo el amplio conocimiento acumulado hasta hoy de las ciencias básicas, nos harían sujetos más críticos en nuestras evaluaciones médicas e intervenciones quirúrgicas; asumiríamos la fenomenología del humano enfermo que siente y piensa con sus repercusiones existenciales. ${ }^{4}$

Por último, quiero dejar claro que este volver a ver a la clínica clásica, no estaría en franca divergencia con la medicina basada en las evidencias, ni excluye el avance en los modernos sistemas de comunicación; todo lo contrario, los megaensayos y metaanálisis deben influir en todo aquello que hace el médico día a día, pero con un espíritu de lógica crítica e innovadora, para evitar la degradación de la libertad del clínico mediante rígidos y dogmáticos protocolos, que a veces orillan a excesivos análisis económicos simplistas y repetitivos, que favorecen más a políticos y administradores que a la salud misma.

\section{REFERENCIAS}

1. Gadamer Hans-Georg. El estado oculto de la salud. Barcelona: Gedisa; 2001.

2. Surós BA, Surós BJ. Semiología médica y técnica exploratoria. 8va ed. Elsevier Masson; 2013. Accesible en: http://labibliotecamedica.brogspot.com

3. Romero SG. Dolor, cerebro y cultura. Dol Clin Ter 2008; $\mathrm{V}(10): 23-24$.

4. Viesca-Treviño C. La medicina: conocimiento y significado. Gac Méd Méx 2009;146(2):167-169.

\footnotetext{
$\triangle$ Correspondencia:

Dr. Douglas Maza-González, Avenida La Luna, lote

7, manzana 6, supermanzana 44. Cancún, Quintana

Roo, México.

Correo electrónico: dmaza98@gmail.com
}

El autor declara no tener conflicto de intereses 